\title{
Predicting relapse in patients with inflammatory bowel disease: what is the role of biomarkers?
}

D S Pardi, W J Sandborn

Faecal calprotectin seems to be a relatively sensitive and specific marker of the risk of relapse in ulcerative colitis, but not in Crohn's disease

$\mathrm{V}$ arious laboratory biomarkers have been studied in inflammatory bowel disease (IBD) as diagnostic aids, indicators of disease activity or severity, and to predict the risk of relapse in those patients in remission. These biomarkers have enormous potential implications for patient management. For example, therapeutic decisions could be directed more appropriately if a marker could reliably distinguish active IBD from other inflammatory or non-inflammatory causes of symptoms, or if one could distinguish Crohn's disease from ulcerative colitis. In addition, a simple, inexpensive, sensitive, specific marker could help monitor response in the clinic and in clinical trials. Finally, the ability to reliably predict the risk of recurrence would help direct appropriate therapy to those who would most likely benefit from it and avoid the expense and potential toxicity of chronic maintenance therapy in those who have a low risk of recurrence. In the current issue of Gut, Costa and colleagues ${ }^{1}$ addressed the latter issue by studying the role of faecal calprotectin as a marker of risk of relapse in ulcerative colitis and Crohn's disease (see page 364). Calprotectin represents $50-60 \%$ of neutrophilic cytosolic protein, is stable in faeces for several days after excretion, and has a relatively easy to perform assay which is available commercially and correlates well with the more difficult and more expensive indium 111-labelled leucocyte excretion $^{2}$

Costa and colleagues ${ }^{1}$ studied 38 patients with Crohn's disease and 41 with ulcerative colitis in remission for a mean of five months. A baseline faecal calprotectin level greater than $150 \mu \mathrm{g} / \mathrm{g}$ had a sensitivity for predicting relapse within the next year of $89 \%$ in ulcerative colitis and $87 \%$ in Crohn's disease. The specificity in ulcerative colitis was $82 \%$ but only $43 \%$ in Crohn's disease. After multivariate analysis, patients with Crohn's disease with a baseline faecal calprotectin greater than $150 \mu \mathrm{g} / \mathrm{g}$ had a non-significant twofold increased likelihood of relapse whereas those with ulcerative colitis and an elevated faecal calprotectin had a significant 14-fold increase risk. $\mathrm{C}$ reactive protein (CRP) and erythrocyte sedimentation rate (ESR), either as single tests or combined with calprotectin, were not useful for predicting relapse.

The results of this study add to the growing body of literature on biomarkers in IBD in general and faecal calprotectin in particular. In previous studies, faecal calprotectin has been shown to be a sensitive marker of activity in Crohn's disease and to correlate well with endoscopic and histological disease activity in ulcerative colitis. ${ }^{3}{ }^{4}$ Faecal calprotectin also normalises along with endoscopic healing in Crohn's disease ${ }^{5}$ and is a very sensitive and specific marker for distinguishing IBD from irritable bowel syndrome (IBS). ${ }^{3}$ The Costa study suggests that calprotectin is a good marker of relapse risk in ulcerative colitis, but not in Crohn's disease, related primarily to poor specificity, and therefore poor positive predictive value. However, a previous study of faecal calprotectin as a marker of relapse risk in IBD found a faecal calprotectin level of $50 \mu \mathrm{g} / \mathrm{g}$ to be a sensitive and specific marker of recurrence risk in both ulcerative colitis and Crohn's disease. ${ }^{6}$ In this study, patients with a faecal calprotectin level greater than $50 \mu \mathrm{g} / \mathrm{g}$ had a 13-fold increased risk of relapse, and the specificity for predicting relapse in Crohn's disease was $83 \%$, compared with $43 \%$ in the Costa study. ${ }^{6}$

The reason(s) for the poorer specificity of calprotectin in the current study are not clear. A different cut off value was used, but the higher cut off in the Costa study would be expected to increase specificity rather than decrease it. The definition of remission and relapse were similar in the two studies, and both used an ELISA assay (although the assays were probably at least slightly different). In the previous study, patients were in remission for 14 months while in the Costa study they were in remission for $1-12$ months. Perhaps the value of calprotectin for predicting relapse in Crohn's disease decreases the longer a patient is in remission.

Several other clinical indices and biological markers have been studied in IBD. These can be divided into clinical disease activity indices, endoscopic indices, serum markers, faecal markers, and miscellaneous tests. Clinical indices, including the Crohn's disease activity index (CDAI) and other disease activity indices for Crohn's disease and ulcerative colitis, are largely subjective and typically cumbersome and have significant interobserver variability. Furthermore, they are not valid in patients with fistulas, stomas, and non-inflammatory causes of symptoms (for example, stenosis, post surgical anatomy). There are also several endoscopic indices of severity. The Crohn's disease endoscopic index of severity ${ }^{7}$ has a poor correlation with clinical activity and treatment induced remission, although complete mucosal healing may predict a favourable course. However, this index is complex and not suitable for routine clinical practice. ${ }^{8}$ The most well known endoscopic index of severity is the Rutgeerts score which is simple and accurately predicts the risk of recurrence after surgical resection.'

A multitude of serum markers have been studied in IBD. Many of these are acute phase reactants (acid $\alpha_{1}$ glycoprotein (orosomucoid)), CRP, fibrinogen, lactoferrin, serum amyloid $\mathrm{A}$, and $\alpha_{1}$ antitrypsin. ${ }^{10}$ In an early study, Brignola and colleagues found that combining acid $\alpha_{1}$ glycoprotein, $\alpha_{2}$ globulin, and ESR into an index resulted in $88 \%$ accuracy in predicting relapse over 18 months in patients with Crohn's disease in remission. ${ }^{11}$ They found no value in baseline levels of haemoglobin, white blood cell count, albumin, iron, or CRP. Other studies have also found limited value for CRP in predicting relapse. ${ }^{1612}$ Data on other markers such as serum and urinary neopterin levels, serum tumour necrosis factor (TNF) $\alpha$ levels, TNF- $\alpha$ receptor levels, and various interleukins (IL-1, IL-6, IL-8), interleukin receptors (IL-2R, IL-6R), or interleukin receptor antagonists (IL-lra) are limited or contradictory. ${ }^{913}$

As serum markers of inflammation can be elevated in a variety of conditions, it seems likely that faecal markers 
of inflammation, in the absence of enteric infection, would be more specific for IBD. Faecal markers can be divided into faecal excretion of leucocytes, serum proteins, or leucocyte products. Faecal excretion of indium 11 1-labelled white blood cells has a good correlation with colitis but not ileitis and has no correlation with CDAI. ${ }^{14}$ These issues, together with the cost, radiation exposure, and limited availability of this technology makes measurement of faecal excretion of indium-labelled white blood cells of limited value clinically.

Faecal excretion of various serum proteins has also been studied in IBD. Perhaps the best studied is faecal $\alpha_{1}$ antitrypsin excretion. However, the data on this protein and its correlation with disease activity and response to therapy are mixed. ${ }^{14}$ More promising is faecal excretion of various leucocyte products. Faecal lysozyme excretion correlates with disease activity and indium 111 white blood cell excretion in colitis but not in ileitis, and it is also elevated in other gastrointestinal inflammatory disorders, limiting its specificity for IBD. ${ }^{14}$ Faecal lactoferrin concentration is increased in active IBD compared with inactive IBD, IBS, and healthy controls. ${ }^{14}{ }^{15}$ In addition, in patients tapering off steroids, persistent elevations in faecal lactoferrin may predict an increased risk of early relapse and therefore may help guide the rapidity of the steroid taper. ${ }^{15}$ Finally, faecal lactoferrin levels may rise significantly prior to a clinically evident relapse and thus may be a good marker to predict subsequent IBD flares. ${ }^{15}$ Other faecal markers, such as elastase, myeloperoxidase, leucocyte esterase, and TNF- $\alpha$, have less promising data. ${ }^{14}$

Several miscellaneous tests have also been studied in IBD. Indium 111 white blood cell scanning can identify and localise active disease and distinguish IBD from IBS and fibrotic from inflammatory strictures. However, labelled leucocyte scans cannot distinguish IBD from other causes of intestinal inflammation and are expensive and involve radiation exposure. ${ }^{16}$

Intestinal permeability can be measured by a variety of methods. Measures of intestinal permeability have $95 \%$ sensitivity for identifying active Crohn's enteritis but only 50\% for colitis. ${ }^{17}$ Intestinal permeability is thought to be a potentially useful measure of response to therapy in Crohn's disease, particularly in the small bowel. ${ }^{16}$ In Crohn's disease, tests of intestinal permeability have a sensitivity of $84-89 \%$ and a specificity of $61-76 \%$ for predicting relapse within one year but only $53 \%$ and $85 \%$, respectively, at four months. ${ }^{8}$ Furthermore, these tests are somewhat time consuming and difficult, with limited availability and therefore are of questionable clinical value.

Other tests that have been used to measure disease activity or to predict relapse include assaying whole gut lavage fluid for immunoglobulin $G$, IL-1B, and IL-8. ${ }^{13}$ However, data on these markers are limited and patient acceptability would likely be low for repeated testing. Others have measured various inflammatory markers, including TNF- $\alpha$ and IL-1B production from stimulated cultured lamina propria mononuclear cells and showed that the degree of production is predictive of relapse over one year. ${ }^{18}$ However, this technology requires mucosal biopsies and therefore application to small bowel disease would be limited. Furthermore, this technique is relatively difficult requiring cell culture and stimulation.

In summary, the current clinical indices or biological markers of disease activity are for the most part too invasive, too difficult, too expensive, or require radiation exposure. Two possible exceptions are faecal calprotectin and faecal lactoferrin excretion, which are relatively simple and inexpensive. Based on two studies to date ${ }^{16}$ faecal calprotectin seems to be a relatively sensitive and specific marker of the risk of relapse in ulcerative colitis. It also appears to be a sensitive marker of relapse risk in Crohn's disease but the data on specificity are conflicting at this point. However, these data need to be interpreted cautiously. The number of studies is small, and in both studies using calprotectin to predict relapse risk, most patients were on medical therapy. Calprotectin may behave differently in patients who are on no therapy. Therefore, before faecal calprotectin or any other biological marker of activity can be incorporated into routine clinical practice, other studies in larger and diverse groups of patients will be necessary to clarify its role further.

Gut 2005;54:321-322.

doi: $10.1136 /$ gut.2004.048850

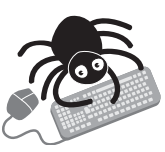

Conflict of interest: declared (the declaration can be viewed on the Gut website at http://www.gutjil.com/ supplemental).

\section{Authors' affiliations}

D S Pardi, W J Sandborn, Inflammatory Bowel Disease Clinic, Division of Gastroenterology and Hepatology, Mayo Clinic College of Medicine, Rochester, Minnesota, USA

Correspondence to: Dr D S Pardi, Mayo Clinic College of Medicine, 200 First Street SW Rochester, MN 55905, USA

pardi.darrell@mayo.edu

\section{REFERENCES}

1 Costa F, Mumolo MG, Ceccarelli L, et al. Calprotectin is a stronger predictive marker of relapse in ulcerative collitis than in Crohn's disease. Gut 2005;54:364-8.

2 Roseth AG, Schmidt TN, Fagerhol MK Correlation between faecel excretion of indium 111 -labeled granulocytes and calprotectin, a granulocyte marker protein in patients with inflammatory bowel disease. Scand J Gastroenterol 1999;34:50-4.

3 Tibble JA, Teahon K, Thiodleifsson B, et al. A simple method for assessing intestinal inflammation in Crohn's disease Gut 2000:47:506-13.

4 Roseth AG, Aadland E, Jahnsen J, et al. Assessment of disease activity in ulcerative colitis by faecal calprotectin, a novel granulocyte marker protein. Digestion 1997;58:176-80.

5 Roseth AG. Determination of faecal calprotectin a novel marker of organic gastrointestinal disorders. Dig Liver Dis 2003;35:607-9.

6 Tibble JA, Sigthorsson G, Bridger S, et al. Surrogate markers of intestinal inflammation are predictive of relapse in patients with inflammatory bowel disease. Gastroenterology 2000;1 19:15-22

7 Mary JY, Modigliani R. Development and validation of an endoscopic index of severity for Crohn's disease: a prospective multicenre study. Gut 1989:30:983-9.

8 Sostegni R, Daperno M, Scaglione N, et al. Review article: Crohn's disease: Monitoring disease activity. Aliment Pharmacol Ther 2003;17(suppl 2):11-17.

9 Rutgeerts P, Geboes K, Vantrappen G, et al Predictability of the postoperative course of Crohn's disease. Gastroenterology 1990;99:956-63.

10 Nielsen OH, Vainer B, Madsen SM, et al. Established and emerging biologic activity markers of inflammatory bowel disease. Am J Gastroenterol 2000;95:359-67.

11 Brignola C, Campieri M, Bazzocchi G, et al. A laboratory index for predicting relapse in asymptomatic patients with Crohn's disease. Gastroenterology 1986;91:1490-4.

12 Boirivant M, Leoni M, Taricotti D, et al. The clinical significance of serum C-reactive protein levels in Crohn's disease. J Clin Gastroenterol 1988;10:401-5

13 Arnott IDR, Watts D, Ghosh S. Review article: is clinical remission the optimum therapeutic goal in the treatment of Crohn's disease? Aliment Pharmacol Ther 2002;16:857-67.

14 van der Sluys Veer A, Biemond I, Verspaget HW, et al. Faecal parameters in the assessment of activity in inflammatory bowel disease. Scand J Gastroenterol 1999;(suppl 230): 106-10.

15 Walker TR, Land ML, Cook TM et al. Serial fecal lactoferrin measurements are useful in the interval assessment of patients with active and inactive inflammatory bowel disease. Gastroenterology 2004; 126:A215.

16 Tibble JA, Biarnason I. Noninvasive investigation of inflammatory bowel disease. World J Gastroenterol 2001 ; 7:460-5.

17 Bjarnason I, MacPherson A, Hollander D. Intestinal permeability: An overview. Gastroenterology 1995;108:1566-81.

18 Schreiber S, Nikolaus S, Hampe J, et al. Tumor necrosis factor alpha and interleukin 1 beta in relapse of Crohn's disease. Lancet 1999;353:459-61. 


\title{
Wireless capsule endoscopy and Crohn's disease
}

\author{
P Swain
}

Wireless capsule endoscopy appears to be superior to all current forms of radiological investigation of the small intestine in detecting the mucosal abnormalities of Crohn's disease

W hen the wireless capsule endoscope (WCE) was introduced, fears that the capsule might become impacted caused early clinical protocols to exclude any patients with a hint of previous subacute obstruction or symptoms suggestive of Crohn's disease. $^{2-6}$ In fact a few patients with Crohn's disease were inadvertently included in these early studies ${ }^{3-6}$ as the symptoms of this disease are often subtle and other investigations are sometimes inconclusive. WCE in a short time has acquired a well established role in the investigation of patients with recurrent gastrointestinal bleeding of obscure origin when gastroscopy and colonoscopy fail to reveal the source. ${ }^{2-6}$ Occult Crohn's disease was found to be a cause of bleeding or anaemia in several of these series. Capsule endoscopy has been used in more than 100000 patients worldwide.

Several comparative studies have shown that WCE could outperform push enteroscopy in finding clinical causes of bleeding. Although the image quality of push enteroscopy is superior in the area it reached, WCE did not miss much that push enteroscopy saw and provided images from the large percentage of the small intestine that could not be reached by push enteroscopy. In five comparisons the capsule found more small intestinal pathology than push enteroscopy $(66 \%, 68 \%, 69 \%, 55 \%, 66 \% v$ $19 \%, 32 \%, 36 \%, 38 \%, 28 \%)^{3-5} 78$ and four of these studies showed statistically significant differences in favour of capsule endoscopy. ${ }^{4578}$

WCE has also performed well in comparisons with small bowel radiology. Just as the numbers of barium meal and barium enemas have atrophied with the widespread availability of gastroscopy and colonoscopy, radiological investigations of small intestinal disease may also wither with the advent of painless less invasive enteroscopy offered by the wireless capsule endoscope.

The first published study on this topic by Costamagna et al in Gastroenterology ${ }^{9}$ comparing capsule endoscopy with radiology in the form of a small bowel meal caused controversy because some felt that WCE was being compared with an inferior radiological investigation. In this study, barium follow through was normal in 17 patients and showed ileal nodularity in three patients. Capsule endoscopy was normal in three patients and showed positive findings in the remaining 17 patients. The barium study was considered diagnostic in four $(20 \%)$ patients. Capsule endoscopy was considered diagnostic in nine (45\%) patients, suspicious in eight $(40 \%)$ patients, and failed in three (15\%) patients. For obscure gastrointestinal bleeding, the diagnostic potential of barium follow through was much worse compared with capsule endoscopy ( $5 \% v$ $31 \%$; p <0.05). Capsule endoscopy was well tolerated and better accepted by patients compared with the most recently performed endoscopic procedure.

Subsequent studies have shown that wireless capsule was also superior to state of the art enteroclysis (small bowel enema) and computed tomography (CT) enteroclysis, which currently constitute the best available radiological investigations for imaging the small bowel.

Liangpunsakul and colleagues ${ }^{10}$ compared state of the art enteroclysis with WCE for its capacity to demonstrate ulcers in the small intestine. There were 40 patients during this study period with negative upper and lower endoscopies and small bowel series. Three patients had multiple small bowel ulcers detected by WCE. The radiologists were told in advance of the WCE findings. Despite this, the enteroclysis studies were negative. All three patients improved after therapy for Crohn's disease. In this study, WCE was more sensitive for small bowel ulcers than the best enteroclysis available.

Voderholzer and colleagues ${ }^{11}$ compared the diagnostic yield of WCE with CT enteroclysis. Twenty two patients with suspected small bowel pathology underwent both CT enteroclysis and wireless capsule enteroscopy examinations, conducted by two independent blinded investigators. The results of the two investigations (diagnoses and number, extent, and location of lesions detected) were compared by a third investigator. Patients included in the study had obscure gastrointestinal bleeding $(\mathrm{n}=8)$, Crohn's disease ( $\mathrm{n}$ $=8)$, unexplained diarrhoea $(\mathrm{n}=5)$, or suspected carcinoid tumour $(\mathrm{n}=1)$. Pathological lesions were detected using capsule enteroscopy in 13 patients (59 $\%)$ and using CT enteroclysis in eight (36\%; $p=0.12$ ). In seven patients (one case each of colonic Crohn's disease, diverticulitis, Meckel's diverticulum, carcinoid tumour, mesothelioma, colonic polyps, and irritable bowel syndrome), no pathological changes were found in the small intestine using either method. The diagnosis was established by wireless capsule enteroscopy in four patients with obscure bleeding whereas CT enteroclysis was positive in only one patient $(p=0.1)$. Crohn's disease was found in two patients with unexplained diarrhoea. Small bowel lesions were identified in six patients with known Crohn's disease using capsule enteroscopy or CT enteroclysis. Wireless capsule enteroscopy detected more small bowel lesions than CT enteroclysis in patients with obscure gastrointestinal bleeding and Crohn's disease.

Enteroclysis with or without CT or magnetic resonance may produce superior images compared with barium follow through but is hated by many patients who find the trans-nasal intubation of the duodenum uncomfortable. Technical improvements in MR have allowed this technology to provide good quality small bowel images using $\mathrm{MR}$ enteroclysis, and contrast swallowed by mouth may provide nearly as good images as those acquired when contrast is administered by nasoduodenal tube. ${ }^{12}$

The surprise to many endoscopists using capsule endoscopy was how some apparently very severe mucosal abnormalities could be missed on good quality radiological studies.

There are now several fully published peer reviewed studies suggesting that Crohn's disease can be diagnosed with capsule endoscopy in patients who have had a negative colonoscopy, gastroscopy, and small bowel barium studies. ${ }^{13-17}$ It may be true that a higher rate of ileoscopy might have increased the rate of diagnosis of Crohn's disease in some of these series. Rates of ileoscopy in large published series of colonoscopy are surprisingly low (for example, 11\% in 9000 patients $^{18}$ ) and it can be difficult to get through the ileocaecal valve, especially if Crohn's disease has altered 


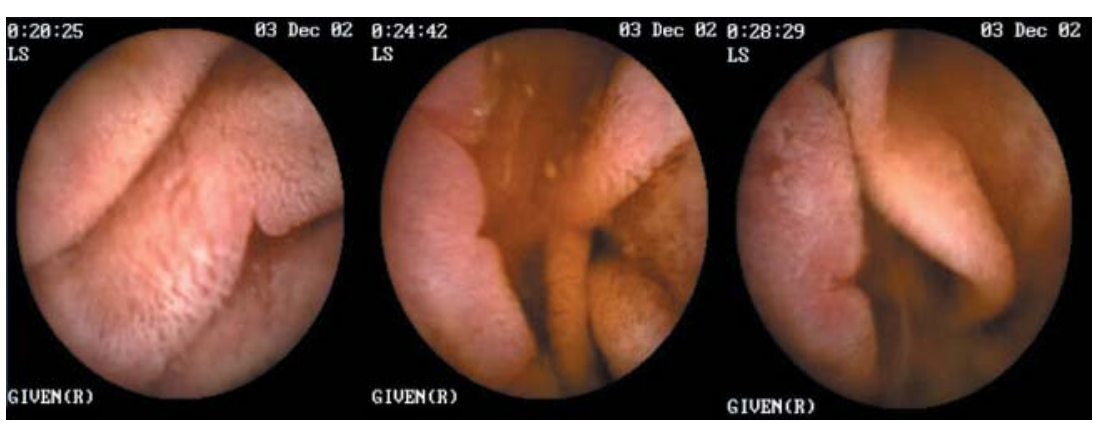

Figure 1 Notching on folds and notching with an inflammatory penumbra. other hand does not always reach the ileocaecal valve because of delayed transit.

It is clear from these and other studies that patients with normal ileoscopy at colonoscopy have been found to have small bowel abnormalities which are thought to be Crohn's disease at capsule endoscopy and appeared to respond to treatment for this condition. Mow and colleagues, ${ }^{16}$ Hume and colleagues, ${ }^{19}$ and Lo $^{20}$ suggested that capsule enteroscopy may be especially helpful in distinguishing Crohn's disease from ulcerative colitis in patients with indeterminate colitis, perhaps especially in those in whom ileal pouch formation is being considered. WCE has also been used in children with gastrointestinal blood loss, anaemia, or abdominal pain, and cases of Crohn's disease are a moderately common finding in this group. ${ }^{21} 22$ In India, WCE was able to provide images of small intestinal tuberculosis which can be difficult to distinguish from Crohn's disease. ${ }^{23}$

In Voderholzer's paper published in this issue of Gut, ${ }^{24}$ the frequency of small intestinal Crohn's disease found by

WCE in a consecutive series of patients with Crohn's was double that detected by CT enteroclysis $(25<12 / 41 ; \mathrm{p}<0.005)$ and these findings led to alteration of management in 10 patients with clinical improvement in all (see page 369). They suggest that the logic of designing slow release treatments that are only effective in the colon and terminal ileum for Crohn's disease may be flawed. Their results also demonstrate that a normal terminal ileoscopy at colonoscopy does not exclude active small bowel Crohn's disease higher up and also that a normal wireless capsule examination does not rule out the diagnosis of Crohn's disease (lesions can be missed or not reached).

Because WCE appears superior to all current forms of radiological investigation of the small intestine in detecting the mucosal abnormalities of Crohn's disease, one might imagine that there would be rapid adoption of this technique which does not expose patients to the hazards of repeated high dose $x$ ray examinations and that radiological methods might be abandoned. There will be some hesitancy to do this for three reasons. There is anxiety that a capsule might become stuck or impacted the anatomy of the valve. WCE on the

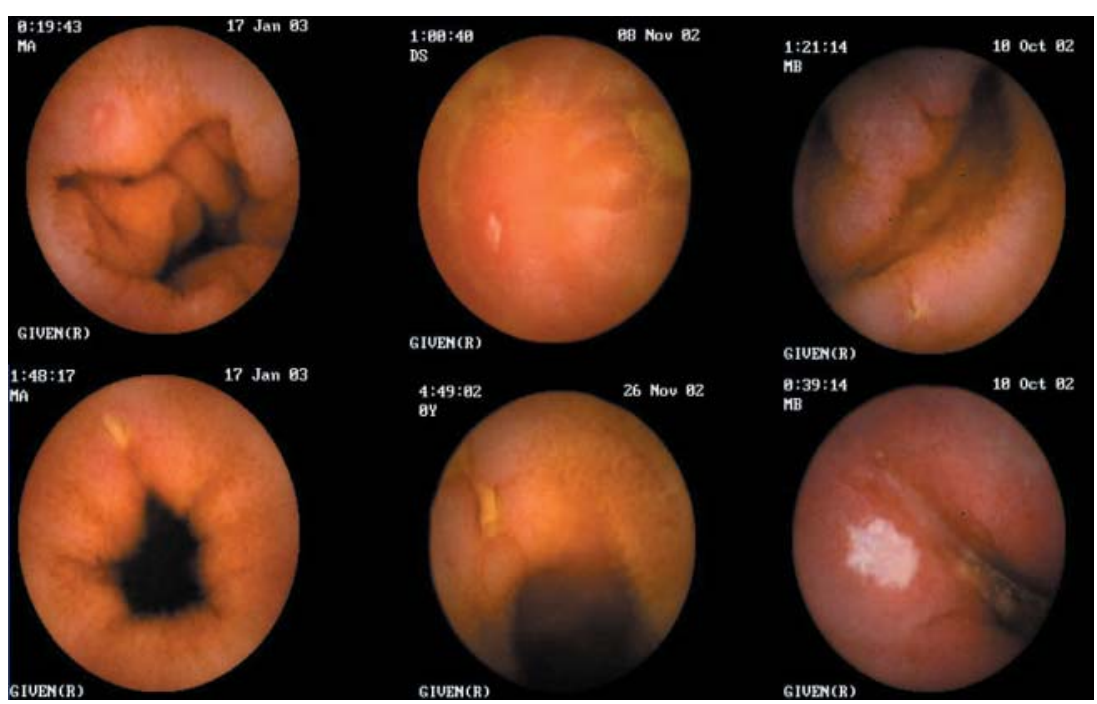

Figure 2 Aphthous and larger ulcers. against a stricture. The costs and manpower implications of changing from small bowel radiology to WCE will slow the rate of uptake. WCE will probably be less good than radiology at detecting fistulae and this might be a reason for occasionally choosing radiological investigations in preference to capsule examinations.

Addressing the stricture issue, capsule impaction does occur and the reported incidence was $2 \%$ in one large pooled series. ${ }^{25}$ Perhaps unexpectedly, most capsule impactions are asymptomatic and rarely produce obstructive symptoms of colicky abdominal pain, failure to pass gas, or vomiting. If the capsule is pointing forwards it may provide good images of the stricture. It is usually possible to tell if the capsule is pointing forwards as it passes through the pylorus and does not usually "tumble" once in the small intestine. For many patients, capsule impaction can be a good outcome as it can lead to surgery which can cure symptoms and also provide histological diagnoses, which are sometimes unexpected. Most recommend that if the capsule examination does not show images of the colon, and the patient does not notice the passage of the capsule in the stool, a plain abdominal $x$ ray should be performed approximately seven days after the examination to check for capsule retention.

It would dampen enthusiasm for the use of wireless capsule examination in Crohn's disease if a radiological study such as a CT enteroclysis had to precede every wireless capsule examination. Alternative options might include the use of a "patency capsule", careful patient selection to avoid patients with symptoms suggestive of subacute obstruction, using capsules on a thread so that the capsule could be retrieved if it got stuck at a stricture, making a smaller diameter capsule, which might also be valuable in small children, and developing better retrieval methods.

A "patency" capsule has been developed (M2A patency; Given, Yoqneam, Israel) to detect possible strictures noninvasively which might lead to capsule retention. This device has identical dimensions to the M2A wireless capsule endoscope. It contains a small transponder in the form of a passive radiofrequency identification tag (RFID) and a dissolving body. Patency is verified if the capsule is excreted intact from the patient's body. Excretion is tested before disintegration with a patency scanner, which emits a radiofrequency signal and detects the presence of the RFID tag in the patient's body. If the capsule is retained in the gastrointestinal tract, it disintegrates into small, mostly soft, 




Figure 3 Crohn's vasculitis.

fragments which can easily pass through strictures

Clinical studies with the patency capsule are available at present in abstract form only. In one study, 61 patients ingested 63 patency capsules: 36 capsules were excreted intact (29/36 in less than 40 hours) and 27 disintegrated in the gastrointestinal tract. Of 54 patients who had radiographically indicated strictures, 31/54 passed the capsules intact. Fifteen patients who tested positively for patency were given the M2A video capsule, all of which passed naturally. ${ }^{26}$ These results suggest that this method might be used in patients with suspected Crohn's disease strictures to allow safe use of the wireless capsule endoscope without prior radiological investigation, even in patients with strictures.

The absence of a "definition" of Crohn's disease causes difficulties. Voderholzer and colleagues ${ }^{24}$ has suggested that the finding of more than 10 aphthous ulcers on a capsule examination is strongly suggestive of Crohn's

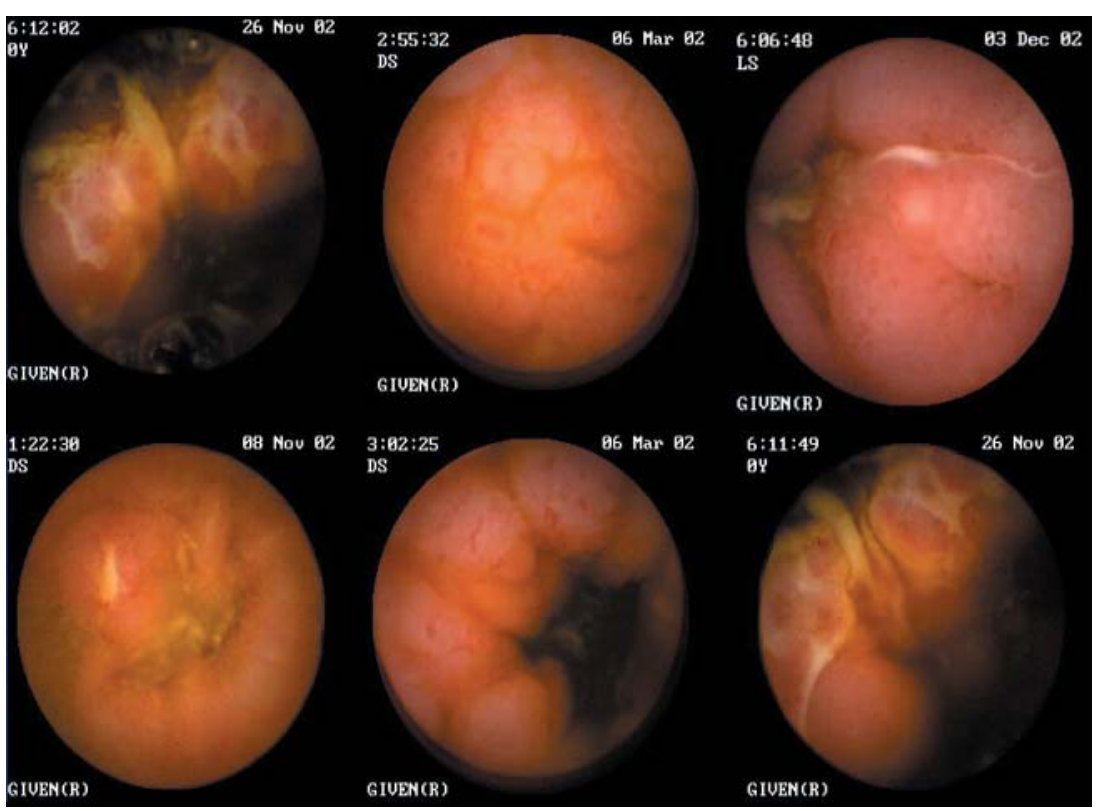

Figure 4 Cobblestone appearances: nodularity with and without ulceration.
It may be possible to categorise early endoscopic appearances of small bowel Crohn's disease from wireless capsule images as follows: notching of folds, a few small aphthous ulcers, larger ulcers, linear ulcers, circumferential involvement, abnormal vascularity, vasculitis, and even cobblestone appearances before radiological involvement can be demonstrated. The images in figs 1-4 were all taken from patients with normal small bowel radiology who improved clinically when treated for Crohn's disease. Location, length of segment involvement, and small bowel transit information can be derived from the capsule images, localisation imager, and timer, although the capsule often does not move at a steady rate and frequently moves in a retrograde fashion.

WCE does not yet feature a biopsy capacity. Such a function would be very valuable for management and diagnosis of small intestinal Crohn's. The advent in Japan of a practical but demanding form of push enteroscopy with a double balloon system has allowed for the first time the possibility of taking directed biopsies under endoscopic visual control from the mid jejunum and upper ileum ${ }^{27}$ without surgery.

There is currently a problem with how best to use capsule endoscopy in patients with abdominal pain or irritable bowel-like syndrome symptoms. Some of these patients may have Crohn's disease or perhaps coeliac disease but most will not have small intestinal pathology. The finding of one or two aphthous ulcers or erosions in patients during capsule endoscopy is common and it is likely that many of these do not have Crohn's disease. It may be clinically expedient at present to avoid using WCE in patients with chronic abdominal pain unless they also have abnormal blood tests or other symptoms such as weight loss, as the incidence of clinically relevant small intestinal pathology is very low while minor clinically irrelevant abnormalities are common. ${ }^{28}$

It seems probable that the wireless capsule will have an increasing role in the investigation and management of Crohn's disease and will be used in preference to radiological investigations using $x$ rays. It is likely to be of most assistance in the early diagnosis, in determining the extent and sites of small intestinal involvement, and in examining patients with indeterminate colitis. It may also be valuable in differentiating Crohn's from other causes of small intestinal disease, find a role as a radiation free method of follow up, and provide evidence about the cause of specific symptoms which 
might in turn lead to more logical therapy. The study published in this issue of Gut suggests that WCE is emerging from an early descriptive phase of astonishment that excellent images of small intestinal Crohn's can be so easily acquired when radiological studies are normal and is beginning to learn how best to take advantage of the information which can be acquired from this technological advance.

Gut 2005;54:323-326.

doi: $10.1136 /$ gut.2004.047282

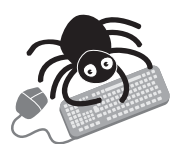

Conflict of interest: declared (the declaration can be viewed on the Gut website at http://www.gutinl.com/ supplemental).

Correspondence to: Dr P Swain, Department of Surgical Oncology and Technology, Imperial College London, St Mary's Hospital, London W2 INY, UK; paulswain1@compuserve.com

\section{REFERENCES}

1 Iddan G, Meron G, Glukhovsky A, et al. Wireless capsule endoscopy. Nature 2000;405:417.

2 Appleyard M, Glukhovsky A, Swain P. Wirelesscapsule diagnostic endoscopy for recurrent smallbowel bleeding. N Engl J Med 2001;344:232-3

3 Lewis BS, Swain P. Capsule endoscopy in the evaluation of patients with suspected small intestinal bleeding: Results of a pilot study. Gastrointest Endosc 2002;56:349-53.

4 Ell C, Remke S, May A, et al. The first prospective controlled trial comparing wireless capsule endoscopy with push enteroscopy in chronic gastrointestinal bleeding. Endoscopy 2002:34:685-9.

5 Mylonaki M, Fritscher-Ravens A, Swain P. Wireless capsule endoscopy: a comparison with push enteroscopy in patients with gastroscopy and colonoscopy negative gastrointestinal bleeding. Gut 2003;52:1122-6.

6 Pennazio M, Santucci R, Rondonotti, et al. Outcome of patients with obscure gastrointestinal bleeding after capsule endoscopy: Report of 100 consecutive cases. Gastroenterology 2004:216:643-53.

7 Mata A, Llach J, Bordas JM, et al. Role of capsule endoscopy in patients with obscure digestive bleeding. Gastroenterol Hepatol 2003;26:619-23.

8 Saurin JC, Delvaux M, Gaudin JL, et al. Diagnostic value of endoscopic capsule in patients with obscure digestive bleeding: Blinded comparison with push enteroscopy. Endoscopy 2003:35:576-84.

9 Costamagna G, Shah SK, Riccioni ME, et al. A prospective trial comparing small bowel radiographs and video capsule endoscopy for suspected small bowel disease. Gastroenterology 2002; 123:999-1005.

10 Liangpunsakul S, Chadalawada V, Rex DK, et al. Wirelewss capsule endoscopy detects small bowel ulcers in patients with normal results from state of the art enteroclysis. Am J Gastroenterol 2003;98: 1295-8

11 Voderholzer WA, Ortner M, Rogalla P, et al. Diagnostic yield of wireless capsule enteroscopy in comparison with computed tomographic enteroclysis. Endoscopy 2003;35:1009-14.

12 Schreyer AG, Geissler A, Albrich H, et al. Abdominal MRI after enteroclysis or with ora contrast in patients with suspedted or proven Crohn's disease. Clin Gastroenterol Hepatol 2004;6:491-7.

13 Scapa E, Jacob H, Lewkowicz S, et al. Initial experience of wireless-capsule endoscopy for evaluating occult gastrointestinal bleeding and suspected small bowel pathology. Am J Gastroenterol 2002;97:2776-9.

14 Fireman Z, Mahajna E, Broide E, et al. Diagnosing small bowel Crohn's disease with wireless capsule endoscopy. Gut 2003;52:390-2.

15 Herrerias JM, Caunedo A, Rodriguez-Tellez M, et al. Capsule endoscopy in patients with suspected Crohn's disease and negative endoscopy. Endoscopy 2003;35:564-8.

16 Mow WS, Lo SK, Targan SR, et al. Initial experience with wireless capsule enteroscopy in the diagnosis and management of inflammatory bowel disease. Clin Gastroenterol Hepatol 2004;2:31-40

17 Ge ZZ, Hu YB, Xiao SD. Capsule endoscopy in diagnosis of small bowel Crohn's disease. World J Gastroenterol 2004;10:1349-52.

18 Bowles CJ, Leicester, R, Romaya C, et al. A prospective study of colonoscopy practice in the UK today: are we adequately prepared for national colorectal cancer screening tomorrow? Gut 2004;53:277-83.

19 Hume G, Whittaker D, Radford-Smith G, et al. Can capsule endoscopy (CE) help differentiate the aetiolgy of indeterminate colitis? Conference proceedings of 3rd International Conference on Capsule Endoscopy, Miami, Florida, 2004;38A

20 Lo SK. Capsule endoscopy in the diagnosis and management of inflammatory bowel disease. Gastrointest Endosc Clin N Am 2004; 14: 179-93.

21 Seidman EG, Sant'Anna AM, Dirks MH. Potential applications of wireless capsule endoscopy in the pediatric age group. Gastrointest Endosc Clin N Am 2004;14:207-17.

22 Arguelles AF, Arguelles MF, Caunedo AA, et al. Utility of capsule endoscopy in pediatric gastroenterology. An Pediatr (Barc) 2003;59:586-9.

23 Reddy DN, Sriram PV, Rao GV, et al. Capsule endoscopy appearances of small-bowel tuberculosis. Endoscopy 2003;35:99.

24 Voderholzer WA, Beinhoelzl J, Rogalla P, et al Small bowel involvement in Crohn's disease: a prospective comparison of wireless capsule endoscopy and computed tomography enteroclysis. Gut 2005:54:369-73.

25 Enns R, Mergender K, Brandabur J, et al. Capsule endoscopy CE: A multicentre, international review and comparison of capsule studies done in three different tertiary-care centres. Gastrointest Endosc 2003:57:AB101.

26 Bolvin $\mathrm{M}$, Lochs $\mathrm{H}$, Voderholzer W, et al Evaluation of the Given patency system in the $\mathrm{Gl}$ tract-results of a multicentre study. Conference proceedings of 3rd International Conference on Capsule Endoscopy, Miami, Florida, 2004;37A.

27 Yamamoto H, Sekine Y, Sato Y, et al. Total enteroscopy with a nonsurgical steerable double balloon method. Gastrointest Endosc 2001;53:216-20.

28 Bardan E, Nadler M, Chowers Y, et al. Capsule endoscopy for the evaluation of patients with chronic abdominal pain. Endoscopy 2003;35:688-9.

\section{Pancreaticobiliary biofilm: is cholesterol the answer?}

\section{R A Kozarek}

Cholesterol stone formation may be a physiological response to limit bacterial biofilm development in bile. Its incorporation into plastic polymers may be a novel way to prevent biofilm development and subsequent stent occlusion in patients with biliary prostheses

B acteria in the biliary tree have been the bane of surgeons and gastroenterologists alike. On the one hand, up to $50 \%$ of patients with chronic cholecystitis have positive bile cultures, as do $75 \%$ of patients with acute cholecystitis, and virtually $100 \%$ of individuals with cholangitis. ${ }^{12}$ On the other hand, gut flora are thought to play a key role in the formation of at least black pigment and mixed gall stones, by virtue of mucus production, and the elaboration of B-glucuronidase that deconjugates bilirubin leading to its precipitation with calcium and palmitate. $^{3-7}$ Moreover, in the form of a biofilm in which bacteria deposit themselves in complex patterns within a mucopolysaccharide or glycocalyx infrastructure, their presence has been associated with progressive occlusion of implanted medical devices which have a lumen and infections resistant to conventional courses of antibiotics. ${ }^{8}$ Plastic biliary stents, most often placed for malignant obstructive jaundice, have also been noted to occlude by virtue of biofilm development. ${ }^{10}$ This biofilm appears to be multidimensional and consists of slime, immunoglobulins, and other proteins in conjunction with multiple bacteria species in the setting of incomplete stent occlusion, and calcium bicarbonate and palmitate 
interlaced within a bacterial matrix with complete stent occlusion..$^{4}{ }^{11-13}$ In either setting, the cholesterol concentration within the stent is relatively low.

Attempts to improve prosthesis patency by use of prophylactic antibiotics, antimucin drugs, ursodeoxycholic acid, and changes in stent polymer have invariably been disappointing. ${ }^{14-16}$ Clinical stent occlusion leads to jaundice and bacterial cholangitis, with polymicrobial infections in up to $90 \%$ of patients in several studies. ${ }^{211} 17$ Recently, similar changes to include polymicrobial bacterial contamination and pancreatic sepsis have been noted in patients with indwelling pancreatic prostheses. ${ }^{18} 19$

In this issue of Gut, Swidsinski and colleague ${ }^{20}$ present elegant insights into the presence of bacterial biofilm and the viability of those bacteria in duodenal, bile duct, and pancreatic duct mucosa as well as in gall stones, common bile duct stones, and biliary stents (see page 388 ). Using oligonucleotide probes, fluorescence in situ hybridisation (FISH) studies were used to characterise bacterial species within a biofilm and three different parameters used to define presumptive bacterial viability: (1) amenability of cells to FISH versus ratio of EUS 338 Cy 3 positive and Gram positive cells (DNA staining); (2) hybridisation time required to achieve fluorescence signal; and (3) time associated with complete exhaustion of fluorescence. Decreased bacterial viability was assumed in the presence of decreased DNA staining, prolonged time to achieve autofluorescence, and rapid exhaustion of fluorescence staining.

Results included the presence of a bacterial biofilm in brown/mixed gall stones, findings supported by Stewart, et al, who noted that $73 \%$ of pigmented gall stones/bile duct stones contained bacteria, ${ }^{4}$ data comparable with those previously noted with black pigment stones. In contrast, no biofilm was noted within the mucosa of 20 gall bladder or five bile duct walls or in the elutes of 132 cholesterol gall stones that were tested.

The latter data can be construed as a different pathogenesis of cholesterol gall stone formation (mucin eliciting cholesterol crystal nucleation in supersaturated bile). ${ }^{21}$ Alternatively, as the authors suggest, it is possible that cholesterol has the potential to inhibit bacterial growth and may actually be a novel mechanism to inhibit bacterial growth within biofilms.

Perhaps the most intriguing findings in the study were the presence of bacterial attachment to pancreatic duct epithelium in seven of nine patients with chronic calcific pancreatitis as well as the dramatic diminution in bacterial viability of bacteria within a biofilm with progressive biliary stent occlusion. Our group has previously noted negative bacterial cultures in patients with chronic calcific pancreatitis at the time of initial manipulation but an average of 3.4 enteric bacteria in aspirated juice once a stent has been placed. ${ }^{18}$ Moreover, we have noted that pancreatic sepsis can occur uncommonly and that prosthesis occlusion is necessary but not a sufficient explanation for why the patient develops infectious complications of pancreatic endotherapy. The findings by Swidsinski et al, that individuals with chronic calcific pancreatitis who have undergone endoscopic therapy develop complex biofilms within the duct epithelium may mean nothing more than exposure of the pancreatic duct to duodenal flora by virtue of stent placement or pancreatic sphincterotomy. ${ }^{20}$ If so, further work should demonstrate that distal bile duct walls have comparable bacterial biofilm in individuals who have undergone biliary sphincterotomy. The latter may or may not play a role in the subsequent development of common bile duct stones seen in a subset of patients, even those with widely patent sphincterotomies. Alternatively, the development of biofilm in patients with chronic calcific pancreatitis may be onerous and associated with increased stone formation, paralleling recent studies demonstrating pancreatic stone protein within biliary stents prior to complete occlusion. ${ }^{11}$

Perhaps the most interesting aspect of the manuscript from a personal standpoint was the finding that bacteria were always above, and not below, the sludge matrix in patients with variably occluded biliary stents, and that bacterial concentrations in patent, but narrowed, stents were higher at the liver, as opposed to the duodenal, end of the prosthesis. In contrast, occluded stents, as well as brown pigment and mixed cholesterol gall stones, were associated with decreased viable bacteria as detectable by FISH, and less than $10 \%$ of the bacteria seen by Gram stain or autofluorescence were amenable to FISH. Had the authors simply cultured the bile proximal to the stent, however, our group as well as others would have shown polymicrobial bacterial contamination that may ultimately result in "stent flu" or frank cholangitis. ${ }^{2} 1718$

The implied conclusion that cholesterol stone formation may be a physiological response to limit bacterial biofilm development in bile and therefore useful to prevent biofilm development and subsequent stent occlusion in patients with biliary prostheses holds some merit. More likely, however, cholesterol coated stents or pharmacological manipulation of biliary excretion of cholesterol would not preclude mucin or protein deposition onto the inner stent surface, findings noted by most authors, prior to bacterial adherence..$^{10-13}$ Nevertheless, Swidsinski et al have added further fuel to the importance of bacterial biofilms and the need to delineate novel therapies to prevent their initiation or preclude their propagation.

Gut 2005;54:326-328.

doi: $10.1136 /$ gut. 2004.048900

Correspondence to: Professor R A Kozarek, Section of Gastroenterology, Virginia Mason Medical Center, 1100 Ninth Ave, Seattle, WA 98101, USA; gasrak@vmmc.org

Conflict of interest: None declared.

\section{REFERENCES}

1 Merchant SS, Falsey AR. Staphylococcus aureus cholecystitis: a report of three cases with review of the literature. Yale J Biol Med 2002;75:285-91.

2 Rerknimitr R, Fogel EL, Kalayci C, et al. Microbiology of bile in patients with cholangitis or cholestasis with and without plastic biliary endoprosthesis. Gastrointest Endosc 2002;56:885-9.

3 Swidsinski A, Lee SP. The role of bacteria in gallstone pathogenesis. Front Biosci 2001;6:E93-103.

4 Stewart L, Ponce R, Oesterle AL, et al. Pigment gallstone pathogenesis: slime production by biliary bacteria is more important than betaglucuronidase production. J Gastrointest Surg 2000;4:547-53.

5 Vitetta L, Best SP, Sali A. Single and multiple cholesterol gallstones and the influence of bacteria. Med Hypotheses 2000;55:502-6.

6 Lu Y, Xiang TH, Shi JS, Zhang BY. Bile anaerobic bacteria detection and antibiotic susceptibility in patients with gallstone. Hepatobiliary Pancreat Dis Int 2003:2:431-4.

7 Konikoff FM, Lechene de la Porte $\mathrm{P}$, Laufer $\mathrm{H}$, et al. Calcium and the anionic polypeptide fraction (APF) have opposing effects on cholesterol crystallization in model bile. J Hepatol 1997:27:707-15.

8 Costerton JW, Cheng KJ, Geesey GG, et al. Bacterial biofilms in nature and disease. Annu Rev Microbiol 1987;41:435-64.

9 Leung JW, Liu Y, Chan RC, et al. Early attachment of anaerobic bacteria may play an important role in biliary stent blockage. Gastrointest Endosc 2000;52:725-9

10 Weickert U, Venzke T, Konig J, et al. Why do bilioduodenal plastic stents become occluded? A clinical and pathological investigation on 100 consecutive patients. Endoscopy 2001;33:786-90.

11 Prat F, Cosson C, Domingo N, et al. Study of the mechanisms of biliary stent occlusion: an analysis of occluded and nonoccluded stents, with emphasis on the role of antinucleating biliary anionic peptide factor. Endoscopy 2004;36:322-8.

12 Zhang H, Tsang TK, Jack CA, et al. Role of bile mucin in bacterial adherence to biliary stents. $J$ Lab Clin Med 2002;139:28-34.

13 Chan FK, Suen M, Li JY, et al. Bile immunoglobulins and blockage of biliary endoprosthesis: an immunohistochemical study. Biomed Pharmacother 1998:52:403-7.

14 Leung JW, Liu YL, Desta TD, et al. In vitro evaluation of antibiotic prophylaxis in the prevention of biliary stent blockage. Gastrointest Endosc 2000;51:296-303.

15 Halm U, Schiefke I, Fleig WE, et al. Ofloxacin and ursodeoxycholic acid versus ursodeoxycholic acid alone to prevent occlusion of biliary stents: a prospective, randomized trial. Endoscopy 2001;33:491-4. 
16 Faigel DO. Preventing biliary stent occlusion. Gastrointest Endosc 2000;51:104-7.

17 Leung JW, Liu YL, Lau GC, et al. Bacteriologic analyses of bile and brown pigment stones in patients with acute cholangitis. Gastrointest Endosc 2001;54:340-5.
18 Kozarek R, Hovde O, Attia F, et al. Do pancreatic duct stents cause or prevent pancreatic sepsis? Gastrointest Endosc 2003:58:505-9.

19 Provansal-Cheylan M, Bernard JP, Mariani A, et al. Occluded pancreatic endoprosthesesanalysis of the clogging material. Endoscopy 1989:21:63-9.
20 Swidsinski A, Schlien P, Pernthaler A, et al. Bacterial biofilm within diseased pancreatic and biliary tracts. Gut 2005:54:388-95.

21 Smith BF. Human gallbladder mucin binds biliary lipids and promotes cholesterol crystal nucleation in model bile. $J$ Lipid Res 1987;28:1088-97.

\section{Predicting survival in early hepatocellular carcinoma}

\section{S Ryder}

\section{Are prognostic models for hepatocellular carcinoma useful in predicting survival?}

O ver the past decade, non-surgical therapies for hepatocellular carcinoma (HCC) occurring on a background of cirrhosis have been established as effective. Hepatic arterial chemoembolisation has a proven survival advantage in selected patient groups, ${ }^{12}$ and there is now strong evidence that ablative therapies, both percutaneous alcohol injection ${ }^{3}$ and radiofrequency ablation, ${ }^{4}$ have survival benefit. In addition, HCC incidence is increasing in the Western world, mainly due to the hepatitis $\mathrm{C}$ epidemic and this cancer now has an increasing impact on health services.

A further change in the clinical setting in which we encounter HCC has occurred. The advent of ablative therapy for HCC, which can destroy tumour nodules up to approximately $5 \mathrm{~cm}$ in diameter, has focused the need for detection of tumours at an early stage in cirrhotic patients and has led to the widespread use of screening in most of the world. There is no doubt that screening using ultrasound and $\alpha$ fetoprotein will detect HCC at a smaller size. ${ }^{5}$ This has produced the need for new prognostic models given that the initial Okuda system ${ }^{6}$ was developed some 30 years ago when the size of HCCs at presentation was substantially larger than today.

Thus prognostic models are important from both a clinical perspective, of being able to give patients and their relatives accurate information on survival, and from a research perspective, to assess outcome of new therapies to help define prognosis as accurately as possible. A number of prognostic models for HCC have been developed. All models have been established in patient cohorts and validated in other cohorts. All available models have established two key factors influencing outcome: how good is the underlying liver function and how extensive is the tumour.

In this issue of Gut, two articles address this issue: one comparing current prognostic models-Cancer of the Liver in Italy (CLIP), ${ }^{7}$ Barcelona Clinic Liver Cancer (BCLC), ${ }^{8}$ and the Okuda system ${ }^{6}$-in a single Italian centre, ${ }^{9}$ and the other by Tateishi and colleagues ${ }^{10}$ assessing a new model developed in a large cohort of Japanese patients (see pages 411 and 419). It should be emphasised that these are not natural history based models; almost all patients had therapy and some patients had more than one treatment modality. This form of modelling of survival therefore reflects the outcome likely to be seen in a real clinic setting but is subject to the impact of many treatment related effects on survival which may not be reproducible in standard clinical practice. It is also important to recognise that these studies were aimed at prognosis in patients with "early" HCC, essentially presymptomatic patients detected primarily by screening, and therefore represent a subgroup of the patient population.

The comparative study, in which $87 \%$ of patients had screening detected HCC, showed that the long established Okuda system is no longer useful in patients with relatively early HCC; not surprising given that Okuda I (early) is defined as less than $50 \%$ of liver volume replaced by tumour, which can still include massive tumours which would be far too large to treat with ablative therapy. The other systems performed well, with the best predictor being the BCLC system. This has the disadvantage of complexity; if strictly followed it requires measurement of portal pressure whereas the CLIP system is simple, uses clinical parameters, and can be used at the bedside. The accuracy of the CLIP model is interesting as many of the same parameters as Okuda (Child-Pugh score and tumour extent) are used, yet simple changes such as the classification of tumours as uni or multifocal dramatically improves its predictive value over Okuda. The Barcelona Clinic Model (BCLC) presents features in more detail with more categories, and uniquely includes performance status, a factor which has been key in predicting response to treatment in most other oncology settings. In large clinical trials of therapy for HCC, the BCLC system would seem to have significant advantages in the level of detail of stratification which is possible. From a clinical perspective, the CLIP score will give patients and clinicians an almost equally reliable guide as to outlook.

The Japanese model was developed entirely in patients treated by ablative therapy, which meant that $93 \%$ of patients had tumours smaller than $5 \mathrm{~cm}$ in diameter. ${ }^{10}$ Again, the analysis produced a simple clinical algorithm based on parameters known to reflect liver function (bilirubin and albumin) and tumour extent (size and number). In this system, the ability of these simple parameters to predict survival was high. The overall five year survival rates varied from almost $80 \%$ in patients with good liver function and small tumours to $15 \%$ in those with poor liver and large or multiple tumours. This model will require further validation; perhaps its major drawback was its validation in a cohort undergoing another form of therapy (surgical resection). However, it was interesting that it still predicted survival in a group being treated with an alternative strategy, suggesting that the parameters used will hold true for most situations where early HCC is being treated. The simplicity of this score is attractive; it only takes into account tumour size and number, albumin, and bilirubin, parameters which will be available for all patients early on in the clinical assessment. It differs from the CLIP score in not using $\alpha$ fetoprotein and portal vein invasion and excludes the other components of the Child Pugh score. Further validation of this system is required to 
see if it performs as well as CLIP and BCLC in other parts of the world, where the aetiology of liver disease may be different, and with treatment modalities such as arterial chemoembolisation.

The overriding importance of tumour size and liver function comes across in all of these scoring systems. The real difference between them is in which components of liver function to include and if tumour size and number is enough or if other factors of tumour extent such as portal invasion are better markers. One area which has not been examined specifically in the models is the cause of death. In patients with advanced liver disease the tumour may be incidental and one would expect that most would die of liver failure. In patients with good liver function the outlook may be much more determined by tumour extension. In this latter group, second tumour development and the potential to treat the underlying liver disease are also likely to affect outcome; there is compelling evidence that therapy for hepatitis $\mathrm{C}$ will reduce cancer incidence. ${ }^{11}$

Perhaps the most important point from both the comparative studies and this new algorithm is that in using a combination of ablative therapy and chemoembolisation survival rates are very high. The best comparator studies were two natural history series in untreated patients with small HCC and good liver function at presentation which showed an approximate three year survival rate of $25 \% .{ }^{12}{ }^{13}$ The three year survival in the Grieco study was $40 \%$ with a comparable aetiology of liver disease. This is in contrast with overall survival values which remain poor worldwide, with only 5-8\% five year survival rates in the USA and Europe. These values emphasise that good results with a change in outcome can be achieved but only if tumours are diagnosed at an early stage on a background of good liver function. The treatment option in patients with decompensated liver disease is limited to liver transplantation and there is no possible therapy for those with both a poorly functioning liver and a large HCC because of the high tumour recurrence rates post transplantation. In most parts of the world, the typical patient with HCC still presents with advanced disease which explains the poor overall survival figures. Can we improve the situation and detect more HCC at a treatable stage? Screening of high risk cirrhotic patients has gained wide acceptance and there is clear evidence that such strategies can detect cancers of a smaller size ${ }^{514}$; this can translate into more treatable HCC with survival rates as high as seen in these two cohorts. ${ }^{15}$ What has not been established is if this strategy can alter overall survival, and if the costs, both financially and psychologically, are worthwhile. The main problems with screening are that a significant minority of HCC patients present with their tumour at the same time as the present with their underlying liver disease, and that the screening tests ( $\alpha$ fetoprotein and ultrasound) are either relatively insensitive for small HCC or very operator dependant. The risk of HCC varies according to sex and the cause of cirrhosis, adding further complexity to the debate. There is a need for studies which better identify patients at risk and examine new modalities of screening, such as magnetic resonance imaging. However, there is no doubt that if small HCC are detected they can be treated. We also have prognostic models which allow both clinical prediction of outcome and clinical trials of therapy to be undertaken.

Gut 2005;54:328-329.

doi: 10.1136/gut.2004.052092

Correspondence to: Dr S Ryder, Queen's Medical Centre, Nottingham, UK; stephen.ryder@

mail.qmcuh-tr.trent.nhs.uk

Conflict of interest: None declared.

\section{REFERENCES}

1 Llovet JM, Real MI, Montana X, et al. Arterial embolisation or chemoembolisation versus symptomatic treatment in patients with unresectable hepatocellular carcinoma: a randomised controlled trial. Lancet 2002;359:1734-9

2 Lo $\mathrm{CM}, \mathrm{Ngan} \mathrm{H}$, Tso WK, et al. Randomized controlled trial of transarterial lipiodol chemoembolization for unresectable hepatocellular carcinoma. Hepatology 2002;35: 1164-71.

3 Castells A, Bruix J, Bru C, et al. Treatment of small hepatocellular carcinoma in cirrhotic patients: a cohort study comparing surgical resection and percutaneous ethanol injection. Hepatology 1993:18:1121-6.

4 Allgaier HP, Deibert P, Zuber I, et al. Percutaneous radiofrequency interstitial thermal ablation of small hepatocellular carcinoma. Lancet 1999;353:1676-7.

5 Solmi L, Primerano AMM, Gandolfi L. Ultrasound follow-up of patients at risk of hepatocellular carcinoma: results of a prospective study in 360 cases. Am J Gastroenterol 1996;91:1189-93.

6 Okuda K, Ohtsuki T, Obata H, et al. Natural history of hepatocellular carcinoma and prognosis in relation to treatment. study of 850 patients. Cancer 1985;56:918-28.

7 The cancer of the liver Italian programme (CLIP) investigators. A new prognostic system for hepatocellular carcinoma: a retrospective study of 435 patients. Hepatology 1998;28:751-5.

8 Llovet JM, Bru C, Bruix J. Prognosis of hepatocellular carcinoma: the BCLC staging classification. Semin Liver Dis 1999;19:329-38.

9 Grieco A, Pompili M, Caminiti G, et al. Prognostic factors for survival in patients with earlyintermediate hepatocellular carcinoma undergoing non-surgical therapy: comparison of Okuda, CLIP, and BCLC staging systems in a single Italian centre. Gut 2005;54:411-8.

10 Tateishi R, Yoshida H, Shiina S, et al. Proposal of a new prognostic model for hepatocellular carcinoma: an analysis in 403 patients. Gut 2005;54:419-25.

11 Kowdley KV. Does interferon therapy prevent hepatocellular carcinoma in patients with chronic hepatitis C? Gastroenterology 1999;1 17:738-9.

12 Barbara L, Benzi G, Galani S. Natural history of small untreated hepatocellular carcinoma in cirrhosis; a multivariate analysis of prognostic factors of tumour growth rate and patient survival. Hepatology 1992;16:132-7.

13 Columbo $M$, Sangiovanni A. The natural history of hepatocellular carcinoma. Ital J Gastroenterol 1992;24:95-9.

14 Oka H, Kuriola N, Kim K. Prospective study of early detection of hepatocellular carcinoma in patients with cirrhosis. Hepatology 1990;12:680-7.

15 Mima S, Sekiya C, Kanagawa H. Mass screening for hepatocellular carcinoma: experience in Hokkaido, Japan. J Gastroenterol Hepatol 1994;9:361-5. 